Prepared for Toxicon

\title{
Update on the Defensive Chemicals of the Little Black Ant, Monomorium minimum (Hymenoptera: Formicidae)
}

Jian Chen ${ }^{\mathrm{a}^{*}}$, Charles L. Cantrell ${ }^{\mathrm{b}}$, David Oi ${ }^{\mathrm{c}}$, Michael J. Grodowitz ${ }^{\mathrm{a}}$

${ }^{a}$ USDA-ARS, National Biological Control Laboratory, 59 Lee Road, Stoneville, MS 38776

${ }^{\mathrm{b}}$ USDA-ARS, Natural Products Utilization Research, University, MS 38677

${ }^{c}$ USDA-ARS, Center for Medical, Agricultural, and Veterinary Entomology, 1600 SW 23rd

Drive, Gainesville, Florida, 32608, USA

* Corresponding author

Jian Chen

USDA-ARS, BCPRU, 59 Lee Road, Stoneville, MS 38776, USA

Tel: 662-686-3066.

Fax: 662-686-5281

E-mail address: jian.chen@ars.usda.gov (J. Chen).

1

(C) 2016. This manuscript version is made available under the Elsevier user license http://www.elsevier.com/open-access/userlicense/1.0/ 


\section{ABSTRACT}

Alkaloids, including 2,5-dialkylpyrrolidines and 2,5-dialkylpyrrolines, have been reported to be components in the venom of little black ants, Monomorium minimum (Buckley). Two fatty amines were recently reported as minor compounds. By analyzing the discharge collected from the stinger apparatus (milking), this study revealed the presence of an additional seven compounds in the defensive secretion of this ant species. Compounds identified were 9-decenyl1-amine, $N$-methylenedecan-1-amine, $N$-methylenedodecan-1-amine, 2-(1-non-8-enyl)-5-(1-hex5-enyl)-1-pyrroline, $N$-methyl-2-(hex-5-enyl)-5-nonanyl-1-pyrrolidine, $\beta$-springene $((E, E)$ 7,11,15-trimethyl-3-methylene-1,6,10,14-hexadecatetraene) and neocembrene $((E, E, E)-1$ isopropenyl-4,8,12-trimethylcyclotetradeca-3,7,11-triene). $\beta$-springene and neocembrene were found only in the defensive secretion of queens. Analyses of the contents of isolated poison and Dufour's glands of the queen indicated that all amines and alkaloids were from the poison gland and that $\beta$-springene and neocembrene were from the Dufour's gland. This demonstrated that the defensive secretion in M. minimum queens consists of components from both glands. This is also the first report on the natural occurrence of 9-decenyl-1-amine, N-methylenedecan-1-amine, and N-methyllenedodecan-1-amine.

Keywords: Little black ants, venom, poison gland, Dufour's gland 


\section{Introduction}

The red imported fire ant, Solenopsis invicta Buren, is an invasive ant species that was introduced into the United States from South America in the 1930's and has become ecologically dominant in areas it infests. Several native ant species have been reported to compete effectively with S. invicta (Baroni Urbani and Kannowski, 1974; Helms and Vinson, 2001; Rao and Vinson, 2004); among them is the little black ant, Monomorium minimum (Buckley) (Smith, 1965;

Thompson, 1990). Little black ants can build their nests close to fire ant colonies and successfully compete with $S$. invicta for food and territory (Thompson, 1990; Rao and Vinson, 2004). Like S. invicta, both workers and queens of M. minimum possess a venom apparatus, also known as a stinger apparatus. The venom apparatus is composed of the sting and two glands, the venom gland and Dufour's gland. When discharged, the venom gland secretion may be accompanied by chemicals from Dufour's gland (Braekman and Daloze, 1988). The venom is used by M. minimum workers in competition with other ants for food and territory (Adam and Traniello, 1981). M. minimum venom has been shown to repel S. invicta workers (Baroni Urbani and Kannowski, 1974) and may be one of several important factor why M. minimum can compete effectively against $S$. invicta.

Alkaloids are the dominant components of M. minimum venom, including; saturated and unsaturated 2,5-dialkyl-pyrrolidines (Jones et al., 1982; Lange et al., 1989), unsaturated 2,5dialkyl-pyrrolines (Lange et al., 1989), and unsaturated N-methyl-2,5-dialkyl-pyrrolidine (Jones et al., 1982). Two primary amines, decylamine and dodecylamine were recently reported (Wang and Chen, 2015) (see Table 1 for the details of compounds that have been published for $M$. minimum). 
It is not unusual for venom compositions to differ between workers and queens, particularly in the proportion of some major components (Maile et al., 2000; Eliyahu et al., 2011; Chen et al., 2015). However, research on venom chemistry in Monomorium species have mainly focused on workers. As part of our effort in searching for insecticidal substances from natural products, we analyzed chemical components in the venom of $M$. minimum for both workers and queens. We report here the discovery of previously unknown compounds and differences in venom composition between workers and queens.

\section{Materials and Methods}

\subsection{Ants}

Ten colonies of Monomorium minimum were collected from Washington County, Mississippi. Colonies were reared in plastic trays with distilled water, $10 \% \mathrm{w} / \mathrm{w}$ sugar water, and mealworm beetle pupae, Tenebrio molitor, under laboratory conditions at $28{ }^{\circ} \mathrm{C}$ and $45 \% \mathrm{RH}$.

\subsection{Venom Composition}

Venom is defined here as the discharge released by ants through the stinger during manual stimulation. Venom was collected directly on a fiber used for solid phase microextraction (SPME) (fused silica fiber with $85 \mu \mathrm{m}$ polyacrylate, Supelco®, Bellefonte, PA). A fine forceps was used to hold an ant until a drop of venom formed on the tip of its stinger (Fig. S1). Under a stereo microscope, the venom was collected by touching the drop with a SPME fiber. The ant was then stimulated to release more venom by gently touching the stinger using the fiber. At least three drops were collected on a fiber from each individual ant. The sample was then directly analyzed using gas chromatography-mass spectrometry (GC-MS). The SPME fiber was 
injected into the GC injection port within $30 \mathrm{~s}$ of venom collection. The absolute concentration of each compound was not determined; however, relative abundances were estimated based on the GC TIC (total ion chromatogram) peak areas without using correction factors. For SPME samples, some alkaloid peaks were not well separated due to their higher concentrations. In order to obtain relative peak area of each alkaloid in relation to the total alkaloid, diluted hexane ant extraction was used to ensure adequate separation of each alkaloid peak in the total ion chromatogram. For those samples, one ant was placed in a $200 \mu 1$ glass conical limited volume insert (J.G Finneran Associates, Inc., Vineland, New Jersey, USA) with $100 \mu 1$ hexane. The ant was then crushed using a micropipette and $2 \mu 1$ liquid was injected into the GC-MS.

\subsection{Gland Content Analysis}

The content of poison and Dufour's glands were analyzed separately for three queens from each of two colonies. For gland removal, queens were pinned dorsal side up on a raised wax-based dissecting tray using a stereo microscope at 7 to $10 \mathrm{x}$ magnification. Individuals were secured through the pronotum using a minuten pin and the abdomen immobilized by laying pins crossways over the narrow pedicle. The poison and Dufour's gland were removed by grasping the terminal abdominal segments or the stinger itself with a fine forceps and pulling posteriorly. After removal, the entire venom apparatus was placed in a drop of phosphate buffered saline on a microscope slide. The poison and Dufour's glands were separated using Vannas Spring Scissors with a $2 \mathrm{~mm}$ cutting edge. After separation each gland was placed in $100 \mu$ dichlormethane and a two microliter sample injected into the GC-MS system. While the poison/ Dufour's gland apparatus was successfully removed from worker ants a clear delineation of the two was not achieved due to the extremely small size of the workers. 


\section{Gas Chromatography - Mass Spectrometry}

The GC-MS system consisted of an Agilent 7890A gas chromatograph with a HP-5 capillary column ( $30 \mathrm{~m} \times 0.25 \mathrm{~mm}$ i.d., $0.25 \mu \mathrm{m}$ film thickness) and an Agilent 5975 mass selective detector. The GC temperature was programmed at an initial temperature of $50{ }^{\circ} \mathrm{C}$, held for 1 min, increased to $240{ }^{\circ} \mathrm{C}$ at a rate of $20{ }^{\circ} \mathrm{C} / \mathrm{min}$ and held for $20 \mathrm{~min}$, and then increased to 280 ${ }^{\circ} \mathrm{C}$ and held for $8 \mathrm{~min}$. Splitless mode was used. Injection temperature was $250{ }^{\circ} \mathrm{C}$, and transfer line temperature was $270{ }^{\circ} \mathrm{C}$. The mass spectrometer was operated at $70 \mathrm{eV}$ in the electron impact mode. Chemical identification was confirmed by comparing the retention times and mass spectra of samples with those of standards that were either purchased commercially or synthesized in our laboratory. 9-decenyl-1-amine was synthesized and $\beta$-springene (purity $\geq$ 95\%) was purchased from Allichem LLC (Baltimore, Maryland, USA). If standards were not available, identification was made by comparison of their mass spectra with those in either NIST library (National Institute of Standards and Technology, USA) or the literature.

\subsection{Synthesis of 9-decenyl-1-amine}

The synthesis scheme for 9-decenyl-1-amine is illustrated in Fig. 1. For synthesis of 1bromo-9-decene (2), 9-decen-1-ol (1, 0.506 g 3.24 mmol, Sigma-Aldrich, St. Louis, MO) was dissolved in $10 \mathrm{~mL}$ of $\mathrm{CH}_{2} \mathrm{Cl}_{2}$ in a $50 \mathrm{~mL}$ three-necked round bottom flask equipped with a condenser. After addition of tetrabromoethane $(1.2806 \mathrm{~g}, 3.86 \mathrm{mmol})$, the reaction mixture was cooled to $0^{\circ} \mathrm{C}$ and triphenylphosphine $(1.0124 \mathrm{~g}, 3.86 \mathrm{mmol})$ was added over a period of 30 minutes. The mixture was warmed to room temperature and refluxed overnight. The reaction mixture was cooled to room temperature and $10 \mathrm{~mL}$ of pentane was added. Triphenylphosphine oxide precipitated as a colorless solid. The suspension was filtered over a $30 \mathrm{~mL}$ fritted funnel 
and the residue was washed with pentane $(3 \times 10 \mathrm{ml})$. The filtrate was evaporated under vacuum to yield a colorless oil. The residue was separated by silica gel column chromatography on a Biotage $100+\mathrm{M}$ column $(40-63 \mu \mathrm{m}, 60 \AA, 39 \times 157 \mathrm{~mm})$ running at $50 \mathrm{~mL} / \mathrm{min}$ using a hexane: EtOAc gradient beginning with 100:0 to $80: 20$ over $1540 \mathrm{~mL}$, followed by 80:20 to 0:100 over $1540 \mathrm{~mL} .22 \mathrm{~mL}$ fractions were collected and recombined based on TLC similarities into compound $2(0.650 \mathrm{~g}, 2.97 \mathrm{mmol}, 92 \%)$. ( ${ }^{1} \mathrm{H} \mathrm{NMR}\left(400 \mathrm{MHz}\right.$ in $\left.\mathrm{CDCl}_{3}\right), \delta 5.74-5.84(\mathrm{~m}, 1 \mathrm{H})$, $4.96 \mathrm{dd}(2 \mathrm{H}, J=2,17), 4.92 \mathrm{dd}(2 \mathrm{H}, J=2,10), 3.38 \mathrm{t}(2 \mathrm{H}, J=7), 1.99-2.05(\mathrm{~m}, 2 \mathrm{H}), 1.79-1.87$ (m), 1.28 (s) ${ }^{13} \mathrm{C}$ NMR (100 MHz, $\left.\mathrm{CDCl}_{3}\right) \delta 139.32,114.39,77.55,77.23,76.91,34.22,33.98$, 33.04, 29.49, 29.21, 29.08, 28.93, 28.37. EI-MS (70eV): 55 (17), 69 (11), 97 (11), 83 (6), 148 (4)).

For synthesis of 1-azidodec-9-ene (3), 1-bromo-9-decene (2, $0.625 \mathrm{~g}, 2.85 \mathrm{mmol})$ was dissolved in $5 \mathrm{~mL}$ dry DMSO in a $50 \mathrm{~mL}$ Schlenk flask under inert gas atmosphere and sodium azide $(0.368 \mathrm{~g}, 5.67 \mathrm{mmol})$ was added. The reaction mixture was stirred at room temperature for 30 minutes and then heated to $60^{\circ} \mathrm{C}$ for 2 hours. The mixture was cooled to room temperature and $5 \mathrm{~mL}$ of $\mathrm{CH}_{2} \mathrm{Cl}_{2}$ and $5 \mathrm{~mL}$ of $\mathrm{H}_{2} \mathrm{O}$ were added. The organic phase was separated, washed with water $(3 \times 5 \mathrm{~mL})$ and dried with $\mathrm{Na}_{2} \mathrm{SO}_{4}$. The solvents were evaporated in a vacuum to yield compound $\mathbf{3}$ as a light yellow oil, which was used in the following reaction step without further purification $(0.326 \mathrm{~g}, 1.79 \mathrm{mmol}, 63 \%)$. $\left({ }^{1} \mathrm{H} \mathrm{NMR}\left(400 \mathrm{MHz}\right.\right.$ in $\left.\mathrm{CDCl}_{3}\right), \delta 5.72-5.82(\mathrm{~m}$, $1 \mathrm{H}), 4.95 \mathrm{dd}(2 \mathrm{H}, J=2,17), 4.91 \mathrm{dd}(2 \mathrm{H}, J=2,10), 3.21 \mathrm{t}(2 \mathrm{H}, J=7), 1.97-2.03(\mathrm{~m}, 2 \mathrm{H}), 1.52-$ $1.59(\mathrm{~m}), 1.26(\mathrm{~s}){ }^{13} \mathrm{C} \mathrm{NMR}\left(100 \mathrm{MHz}, \mathrm{CDCl}_{3}\right) \delta 139.24,114.32,77.55,77.23,76.91,51.61$, 33.91, 29.45, 29.24, 29.14, 29.01, 28.97, 26.84. EI-MS (70eV): 55 (11), 122 (8), 70 (8), 69 (6), $56(6))$. 
For synthesis of 9-decen-1-amine (4), in a $250 \mathrm{~mL}$ three necked round bottom flask equipped with a condenser and $50 \mathrm{~mL}$ of dry THF were cooled to $0{ }^{\circ} \mathrm{C}$ in an ice/water bath. $\mathrm{LiAlH}_{4}$ $(0.303 \mathrm{~g}, 7.98 \mathrm{mmol})$ was added slowly to produce a grey suspension, which was stirred for 5 minutes. 1-azido-9-decene $(\mathbf{3}, 0.818 \mathrm{~g}, 4.51 \mathrm{mmol})$ was dissolved in $10 \mathrm{~mL}$ dry THF and slowly added to the $\mathrm{LiAlH}_{4}$ suspension over a period of 20 minutes, stirred for another 30 minutes at 0 ${ }^{\circ} \mathrm{C}$ and then refluxed for an additional 1.5 hours. The reaction mixture was cooled to $0{ }^{\circ} \mathrm{C}$ and water was subsequently added drop-wise until hydrogen gas evolution ceased. After further addition of $10 \mathrm{~mL} \mathrm{H}_{2} \mathrm{O}$ and $5 \mathrm{~mL}$ of $20 \%$ aq. $\mathrm{NaOH}$ solution, the suspension filtered over a Büchner funnel. The residue was rinsed with $25 \mathrm{~mL}$ THF. The filtrates were combined and the solvents were evaporated in a vacuum to a volume of about $30 \mathrm{~mL}$. $50 \mathrm{~mL}$ of $\mathrm{CH}_{2} \mathrm{Cl}_{2}$ and $50 \mathrm{~mL}$ of $\mathrm{H}_{2} \mathrm{O}$ were added, the organic phase separated and dried over $\mathrm{MgSO}_{4}$. The solvents were evaporated in a vacuum to yield compound $4(0.406 \mathrm{~g}, 2.61 \mathrm{mmol}, 58 \%)$ as a light yellow oil, which solidified over 3 days $\left({ }^{1} \mathrm{H}\right.$ NMR $\left(500 \mathrm{MHz}\right.$ in $\left.\mathrm{CDCl}_{3}\right), \delta 5.75-5.83(\mathrm{~m}, 1 \mathrm{H}), 4.97 \mathrm{~d}(1 \mathrm{H}, J$ $=17), 4.91 \mathrm{~d}(1 \mathrm{H}, J=10), 2.77 \mathrm{t}(1 \mathrm{H}, J=7), 2.00-2.04(\mathrm{~m}, 2 \mathrm{H}), 1.53-1.57(\mathrm{~m}), 1.27(\mathrm{~s}){ }^{13} \mathrm{C}$ $\operatorname{NMR}\left(125 \mathrm{MHz}, \mathrm{CDCl}_{3}\right) \delta$ 139.04, 114.16, 77.33, 77.08, 76.82, 41.11, 33.76, 31.06, 29.41, 29.29, 29.05, 28.88, 26.80. EI-MS (70eV): 55 (9), 56 (8), 114 (5), 67 (5), 86 (4)).

\section{Results}

\subsection{Venom of workers}

In addition to 2,5-dialkylpyrrolines, 2,5-dialkylpyrrolines and fatty amines, 9-decenyl-1amine, $N$-methylenedecan-1-amine and $N$-methylenedodecan-1-amine were identified (Fig 2 and 3). The identity of 9-decenyl-1-amine was confirmed using the synthetic standard. Both retention time and mass spectra were matched between the sample and standard (Fig. S2). The 
identity of N-methylenedecan-1-amine and N-methylenedodecan-1-amine were confirmed by direct comparison of the MS with the corresponding compound in the NIST library search (Fig. S3 and S4). Three 2,5-dialkylpyrrolines, three 2,5-dialkylpyrrolidines, and two N- 2,5dialkylpyrrolidines were identified, including 2-(1-non-8-enyl)-5-(1-hex-5-enyl)-1-pyrroline (Fig. S5), 2-(1-hex-5-enyl)-5-(1-non-8-enyl)-1-pyrroline (Fig. S6), 2-(1-hex-5-enyl)-5-nonanyl1-pyrroline (Fig. S7), 2-(hex-5-enyl)-5-(1-non-8-enyl)pyrrolidine (Fig. S8), 2-(hex-5-enyl)-5nonanylpyrrolidine (Fig. S9), 2-hexyl-5-nonanylpyrrolidine (Fig. S10), N-methyl-2-(hex-5-enyl)5-(1-non-8-enyl)pyrrolidine (Fig. S11), and N-methyl-2-(hex-5-enyl)-5-nonanylpyrrolidine (Fig. S12). The relative peak areas of these identified compounds are shown in Table S1 and Fig. S15. The venom composition seemed to be dominated by 2-(hex-5-enyl)-5-(1-non-8-enyl)pyrrolidine (39.0\%) and 2-(hex-5-enyl)-5-nonanylpyrrolidine (55.4\%). Since the relative peak area of 2-(1non-8-enyl)-5-(1-hex-5-enyl)-1-pyrroline and N-methyl-2-(hex-5-enyl)-5-nonanyl-1-pyrrolidine was very low $(<0.004 \%)$ and not detected in every sample, they were not included in calculating the relative peak area of each alkaloid (Fig. 4). All amines and alkaloids found in the whole worker extract also exist in the collected venom.

\subsection{Venom of queens}

The queen venom did not contain 2-hexyl-5-nonanylpyrrolidine. In addition to 2,5dialkylpyrrolines, 2,5-dialkylpyrrolines, decylamine, and dodecylamine; 9-decenyl-1-amine, Nmethylenedecan-1-amine and N-methylenedodecan-1-amine, $\beta$-springene $((E, E)-7,11,15$ trimethyl-3-methylene-1,6,10,14-hexadecatetraene) and neocembrene ((E,E,E)-1-isopropenyl4,8,12-trimethylcyclotetradeca-3,7,11-triene) were also identified. Identity of $\beta$-springene was confirmed by a synthetic standard (Fig. S13). The identity of neocembrene was confirmed by 
comparing the mass spectrum of the sample with that in the literature. This compound has been reported in the queen of the pharaoh ant, Monomorium pharaonis (Edward and Chambers, 1984). Extracts of $M$. pharaonis were also analyzed using the same GC-MS conditions. The retention time and mass spectrum of neocembrene in $M$. pharaonis were matched to those of neocembrene in M. minimum queen (Fig. S14). The relative peak areas of identified compounds are shown in Table S1. The venom composition seemed to be dominated by 2-(hex-5-enyl)-5-(1-non-8enyl)pyrrolidine (81.3\%), followed by 2-(hex-5-enyl)-5-nonanylpyrrolidine (7.5\%) (Fig. S15). Since 2-(1-non-8-enyl)-5-(1-hex-5-enyl)-1-pyrroline and N-methyl-2-(hex-5-enyl)-5-nonanyl-1pyrrolidine was detected in only a minimal number of queen venom samples, they were not included in calculating the relative peak area of each alkaloid (Fig. S15). $\beta$-springene and neocembrene were only found in the Dufour's gland. Stinger apparatus with poison and Dufour's glands of M. minimum queen is shown in Fig. 4.

\section{Discussion}

To our knowledge, 9-decenyl-1-amine, N-methylenedecan-1-amine, and Nmethyllenedodecan-1-amine have never been reported as naturally occurring compounds. Two fatty amines, decylamine and dodecylamine, from $M$. minimum were reported to be insecticidal against the red imported fire ants (Wang and Chen, 2015). Dodecylamine repelled the common house fly, Musca domestica (Ralston and Barrett, 1941) and decylamine repelled the honey bee, Apis mellifera (Atkins et al., 1975). Dodecylamine deterred oviposition of European corn borer, Ostrinia nubilalis (Binder and Robbins, 1997). Decylamine and dodecylamine also showed high nematicidal activity against pine wood nematode, Bursaphelenchus Lignicolus (Nagase et al., 1982). Due to its similarity in structure to decylamine, 9-decenyl-1-amine may also have similar 
toxic and repellant effects. Both $\mathrm{N}$-methylenedecan-1-amine and N-methyllenedodecan-1-amine have a carbon-nitrogen double bond in their chemical structures, an imine functional group. Toxicity data of these two amines are not available in the literature. What functions they may serve in the ant venom warrants further research.

This study has demonstrated a clear difference in venom composition between workers and queens. $\beta$-springene and neocembrene were found only in the venom of queens while 2-hexyl-5nonanylpyrrolidine did not occur in the queen. $\beta$-springene, a diterpene, was originally isolated from a skin (dorsal) gland of the springbok antelope, Antidorcas marsupialis, from Africa (Burger et al., 1978, 1981). It has been found in other mammals such as the white-lipped peccary, Tayassu pecari (Waterhouse et al., 2001), and collared peccary, Tayassu tajacu (Waterhouse et al., 1996); two reptilians, Cuvier's dwarf caiman, Paleosuchus palpebrosus, and the smooth-fronted caiman, Paleosuchus trigonatus (Schulz et al., 2003); four species of oribatid mites, Oribotritia banksi, O. berlesei, O. hermanni, and O. storkani (Raspotnig et al., 2011); five species of bumblebees, Bombus griseocollis (Bertsch et al., 2004), B. hypnorum (Cahlikova et al., 2004), B. morrisoni, B. rufocinctus (Bertsch et al., 2008), B. semenoviellus (Hovorka et al., 2006); and two stingless bees, Melipona beecheii (Cruz-López, et al., 2005) and Nannotrigona testaceicornis (Pianaro et al., 2009). $\beta$-springene was also found in the Dufour's gland of the ectoparasitoid Habrobracon hebetor (Say) where its abundance varied significantly with age (Howard et al., 2003). The only ant species that has been reported to produce $\beta$-springene is the Old World army ant, Aenictus rotundatus (Oldham et al., 1994). However, its isomer, E,E,E- $\alpha-$ springene, was found in the Dufour's gland of the Dinosaur ant, Nothomyrmecia macrops (Billen et al., 1988). The secretion of Dufour's gland of ants can have multiple functions (Morgan, 
2008). The potential function of $\beta$-springene in the venom of $M$. minimum queens can only be elucidated by further experimentation.

There are several synonyms for neocembrene. The chemical structure of neocembrene was first assigned by Shmidt et al. (1970) while studying the diterpene hydrocarbons of the oleoresin in Siberian spruce, Picea obvata (Ledb.) and Korean pine, Pinus koraensis (Sieb Zucc.). Neocembrene was found by Moore (1966) as the trail pheromone of Nasutitermes exitiosus (Hill); however, the chemical structure of neocembrene in N. exitiosus was not elucidated until 1972 (Birch et al., 1972). Due to a slight difference in NMR spectrum compared to those of neocembrene from two conifers mentioned above, it was then named as neocembrene-A. Neocembrene was also isolated from the gum-resin of Commiphora mukul (Hook, ex Stocks) Engl and it was named as cembrene-A (Patil et al., 1973). Since its discovery, it has been found in numerous plants, corals, insects, and mammals. Vanderah et al. (1978) found it in soft coral, Nephthea species. In addition to N. exitiosus, neocembrene was found in 16 other termite species which are belong to 7 different genera, including Constrictotermes cyphergaster (Silvestri), Nasutitermes corniger (Motschulsky), N. ephratae (Holmgren), N. exitiosus, N. guayanae, N. kemneri, $N$. lujae, $N$. voeltzkowi, Trinervitermes geminates (Sillam-Dussès et al., 2010), and $T$. trinervoides. (Sillam-Dussès et al., 2010), Cubitermes umbratus (Wiemer et al., 1979), Crenetermes mixtus (Prestwich, 1979), N. costalis (Hall and traniello, 1985), Noditermes wasambaricus (Meinwald, et al., 1978), Prorhinotermes canalifrons (Sillam-Dussès et al. , 2005), P. simplex (Sillam-Dussès et al. , 2009), T. bettonianus (McDowell and Oloo, 1984). Neocembrene was found in only two insect species outside isoptera: a sandfly, Lutzomyia longipalpis (Hamilton et al., 2004) and a myrmicine ant, Monomorium pharaonis (Edwards and Chambers, 1984). Neocembrene has exhibited cytotoxicity against A549 (human lung 
adenocarcinoma), HT-29 (human colon adenocarcinoma), KB (human epidermoid carcinoma), and P-388 (mouse lymphocytic leukemia) cell lines (Duh et al., 1999). In M. pharaonis, neocembrene was found only in the Dufour's gland of the fertile queens. Since alates and young queens do not contain neocembrene, its potential role in suppressing the development of new sexual forms (males and queens) in an ant colony was suggested (Edwards and Chambers, 1984). The function of neocembrene in M. minimum is another interesting area and more research is warranted.

2,5-dialkylpyrrolidines are dominant components of $M$. minimum venom for both workers and queens. 2-(hex-5-enyl)-5-(1-non-8-enyl)pyrrolidine and N-methyl-2-(hex-5-enyl)-5-(1-non8-enyl)pyrrolidine were reported in M. minimum by Jones et al. (1982). Lange et al. (1989) reported the following 5 alkaloids in this species, including 2-(1-hex-5-enyl)-5-(1-non-8-enyl)-1pyrroline, 2-(1-hex-5-enyl)-5-nonanyl-1-pyrroline, 2-(hex-5-enyl)-5-(1-non-8-enyl)pyrrolidine, 2-(hex-5-enyl)-5-nonanylpyrrolidine, and 2-hexyl-5-nonanylpyrrolidine. The presence of all these alkaloids were confirmed in this study. In addition, it is the first time that 2-(1-non-8enyl)-5-(1-hex-5-enyl)-1-pyrroline and N-methyl-2-(hex-5-enyl)-5-nonanyl-1-pyrrolidine were identified in the venom of M. minimum. However, both alkaloids have been found in other ant species in the genus of Monomorium. 2-(1-non-8-enyl)-5-(1-hex-5-enyl)-1-pyrroline was found in M. near metoecus, $M$. virdum, and M. ebeninum and N-methyl-2-(hex-5-enyl)-5-nonanyl-1pyrrolidine in $M$. near metoecus, M. virdum, M. near emersoni, and M. cyaneum (Jones et al., 1982). Both 2,5-dialkyl-pyrrolidines and 2,5-dialkyl-pyrrolines are insecticidal (Bacos et al., 1988).

This study demonstrates that the venom in $M$. minimum queen consists of products from both the poison glands and the Dufour's glands. Due to the extremely small size of the workers, 
separation of the poison gland from the Dufour's gland in workers was not successful. Except 2hexyl-5-nonanylpyrrolidine, all compounds found in worker's venom were also found in queen's poison gland. Although the possibility of Dufour's gland origin couldn't be completely ruled out, all the identified compounds for workers are most likely from the poison gland.

Defense is very important to the survival of an ant colony. Many ant species depend on chemicals for their defense. The results of this study extend our knowledge about chemicals produced in the venom of M. minimum, which will help advance our understanding of its biology. 


\section{Acknowledgments}

We thank Dr. Hamed K. Abbas, Biological Control of Pests Research Unit, USDA-ARS, Stoneville, MS and Dr. Aijun Zhang, Invasive Insect Biocontrol and Behavior Laboratory, USDA-ARS, Beltsville, MD for critical review of this manuscript. We thank Mr. Leon Hicks for his technical assistance. Mention of trade names or commercial products in this publication is solely for the purpose of providing specific information and does not imply recommendation or endorsement by the U. S. Department of Agriculture. 


\section{References}

Adams, E.S., Traniello, J. F. A., 1981. Chemical interference competition by Monomorium minimum (Hymenoptera: Formicidae). Oecologia 51, 265-270.

Atkins, E.L., Macdonald, R.L., Greywood-Hale, E.A., 1975. Repellent additives to reduce pesticide hazards to honey bees: field tests. Environ. Entomol. 4, 207-210.

Bacos, D., Basselier, J.J., Celerier, J.P., Lange, C., Marx, E., Lhommet, G., Escoubas, P., Lemaire, M., Clément, J.L., 1988. Ant venom alkaloids from Monomorium species: natural insecticides. Tetrahedron Lett. 29, 3061-3064.

Binder, B.F., Robbins, J.C., 1997. Effect of terpenoids and related compounds on the oviposition behavior of the European corn borer, Ostrinia nubilalis (Lepidoptera: Pyralidae). J. Agric. Food Chem. 45, 980-984.

Baroni Urbani, C., Kannowski, P.B., 1974. Patterns in the red imported fire ant settlement of a Louisiana pasture: some demographic parameters, interspecific competition and food sharing. Environ. Entomol. 3, 755-760.

Bertsch, A., Schweer, H., Titze, A., 2008. Chemistry of the cephalic labial gland secretions of male Bombus morrisoni and B. rufocinctus, two North American bumblebee males with perching behavior. J. Chem. Ecol. 34, 1268-1274.

Bertsch, A., Schweer, H., Titze, A., 2004. Analysis of the labial gland secretions of the male bumblebee Bombus griseocollis (Hymenoptera: Apidae). Z. Naturforsch. C. 59, 701-707.

Billen, J., Jackson, B.D., Morgan, E.D., 1988. Secretion of the dufour gland of the ant Nothomyrmecia macrops (Hymenoptera:Formicidae). Experientia. 44, 715-719.

Birch, A.J., Brown, W.V., Corrie, J.E.T., Moore, B.P., 1972. Neocembrene-A, a termite trail pheromone. J. Chem. Soc., Perkin Trans. 1 21, 2653-2658. 
Burger, B.V., Le Roux, M., Spies, H.S.C., Truter, V., Bigalke, R.C., 1981. Mammalian pheromone studies. IV. Terpenoid compounds and hydroxy esters from the dorsal gland of the springbok, Antidorcas marsupialis. Z. Naturforsch. C. 36, 340-343.

Burger, B.V., Le Roux, M., Spies, H.S.C., Truter, V., 1978. Mammalian pheromone studies - III. (E,E)-7,11,15-trimethyl-3-methylenehexadeca-1,6,10,14-tetraene, a new diterpene analogue of beta-farnesene from the dorsal gland of the springbok, Antidorcas marsupialis. Tetrahedron Lett. 52:5221-5224.

Cahlikova, L., Hovorka, O., Ptacek, V., Valterova, I., 2004. Exocrine gland secretions of virgin queens of five bumblebee species (Hymenoptera: Apidae, Bombini). Z. Naturforsch. C. $59,582-589$.

Chen, L., Lu, Y.-Y., Hu, Q.-B., Fadamiro, H.Y., 2012. Similarity in venom alkaloid chemistry of alate queens of imported fire ants: implication for hybridization between Solenopsis richteri and S. invicta in the Southern United States. Chem. Biodivers. 9, 702-13.

Cruz-López, L., Malo, E.A., Morgan, E.D., Rincon, M., Guzman, M., Rojas, J.C., 2005. Mandibular gland secretion of Melipona beecheii: chemistry and behavior. J. Chem. Ecol. 31, 1621-1632.

da Silva, C.M., da Silva, D.L., Modolo, L.V., Alves, R.B., de Resende, M.A., Martins, C.V.B., de Fa' tima A., 2011. Schiff bases: A short review of their antimicrobial activities. J. Adv. Res. 2, 1-8.

Duh, C.Y., Wang, S.K., Weng, Y.L., Chiang, M.Y., Dai, C.F., 1999. Cytotoxic terpenoids from the Formosan soft coral Nephthea brassica. J. Nat. Prod. 62, 1518-1521.

Edwards, J.P., Chambers, J., 1984. Identification and source of a queen-specific chemical in the pharaoh's ant, Monomorium pharaonis (L.). J. Chem. Ecol. 10, 1731-1747. 
Eliyahu, D., Ross, K.G., Haight, K.L., Keller, L., Liebig, J., 2011. Venom alkaloid and cuticular hydrocarbon profiles are associated with social organization, queen fertility status, and queen genotype in the fire ant Solenopsis invicta. J. Chem. Ecol. 37, 1242-54.

Hall, P., Traniello, J.F.A., 1985. Behavioral bioassays of termite trail pheromones. Recruitment and orientation effects of cembrene-A in Nasutitermes costalis (Isoptera: Termitidae) and discussion of factors affecting termite response in experimental contexts. J. Chem. Ecol. 11, 1503-1513.

Hamilton, J.G.C., Brazil, R.P., Maingon, R., 2004. A fourth chemotype of Lutzomyia longipalpis (Diptera: Psychodidae) from Jaíbas, Minas Gerais State, Brazil. J. Med. Entomol. 41, 1021-1026.

Helms, K.R., Vinson, S.B. Coexistence of native ants with the red imported fire ant, Solenopsis invicta. Southwest. Natur. 46, 396-399.

Holway, D. A., 1999. Competitive mechanisms underlying the displacement of native ants by the invasive Argentine ant. Ecology 80, 238-251.

Honda, K., and Hayashi, N. 1995. Chemical nature of larval osmeterial secretions of papilionid butterflies in the genera Parnassius, Sericinus and Pachliopta. J. Chem. Ecol. 21:859-867

Hovorka, O., Valterova, I., Rasmont, P., Terzo, M., 2006. Male cephalic labial gland secretions of two bumblebee species of the subgenus Cullumanobombus (Hymenoptera: Apidae: Bombus latreille) and their distribution in central Europe. Chem. Biodiv. 3, 1015-1022.

Howard, R.W., Baker, J.E., Morgan E.D., 2003. Novel diterpenoids and hydrocarbons in the Dufour gland of the ectoparasitoid Habrobracon hebetor (Say) (Hymenoptera: Braconidae. Arch. Insect Biochem. Physiol. 54, 95-109.

Jones, T. H., Blum, M.S., Howard, R.W., McDaniel, C.A., Fales, H.M., DuBois, M.B., Torres, 
J., 1982. Venom chemistry of ants in the genus Monomorium. J. Chem. Ecol. 8, 285-300.

Lange, C., Celerier, J.P., Lhommet, G., Basselier, J.J., Lemaire, M., Escoubas, P., Clément, J.L., 1989. Analysis of worker Monomorium minimum ant's venom using gas chromatography/mass spectrometry and gas chromatography/tandem mass spectrometry. Biomed. Environ. Mass Spectr. 18, 780-786.

McDowell, P.G., Oloo, G.W., 1984. Isolation, identification, and biological activity of trailfollowing pheromone of termite Trinervitermes bettonianus (Sjostedt) (Termitidae: Nasutitermitinae). J. Chem. Ecol. 10, 835-851.

Maile, R., Jungnicke, H., Morgan, E.D., Ito, F., Billen, J., 2000. Secretion of venom and Dufour glands in the ant Leptogenys diminuta. J. Chem. Ecol. 26, 2497-2506

Meinwald, J., Prestwich, G., Nakanishi, K., Kubo, I., 1978. Chemical ecology: results from East Africa. Science. 199, 1167-1173.

Moore, B.P., 1966. Isolation of the scent-trail pheromone of an Australian termite. Nature 211, 746-747.

Morgan, E.D., 2008. Chemical sorcery for sociality: Exocrine secretions of ants (Hymenoptera: Formicidae). Myrmecol. News 11, 79-90.

Nagase, A., Kuwahara, Y., Tominaga, Y., Sugawara, R., 1982. Nematicidal activity of akylamine against the pine wood nematode, Bursaphelenchus Lignicolus. Agric. Biol. Chem. 46, 167-172.

Oldham, N.J., Morgan, E.D, Gobin, B., Schoeters, E., Billen, J., 1994. Volatile secretions of an Old World army ant, Aenictus rotundatus, and chemotaxonomic implications of army ant Dufour gland chemistry. J. Chem. Ecol. 20, 3297-3305.

Patil, V.D., Nayak, U.R., Dev, S., 1973. Chemistry of ayuvedie crude drugs-II Guggulu (resin 
from Commiphora mukul), 2: Diterpenoid constituents. Tetrahedron 29, 341-348.

Pianaro, A., Menezes, C., Kerr, W.E., Singer, R.B., Patricio, E.F.L.R.A., Marsaioli, A.J., 2009. Stingless bees: chemical differences and potential functions in Nannotrigona testaceicornis and Plebeia droryana males and workers. J. Chem. Ecol. 35, 1117-1128.

Prestwich, G.D. 1979. Chemical defense by termite soldiers. J. Chem. Ecol. 5, 459-480.

Rao, A., Vinson, S.B., 2004. Ability of resident ants to destruct small colonies of Solenopsis invicta (Hymenoptera: Formicidae). Environ. Entomol. 33, 587-598.

Raspotnig, G., Leutge, V., Krisper, G., Leis, H.-J., 2011. Discrimination of Oribotritia species by oil gland chemistry (Acari, Oribatida). Exp Appl Acarol. 54, 211-224.

Schulz, S., Krueckert, K., Weldon, P.J., 2003. New terpene hydrocarbons from the Alligatoridae (Crocodylia, Reptilia). J. Nat. Prod. 66, 34-38.

Shmidt, E.N., Kashtanova, N.K., Pentegov, V.A., 1970. Neocembrene-a a new diterpene hydrocarbon from Picea obovata and Pinus koraensis. Chem. Nat. Comp. (Part 2) 6, 705707.

Sillam-Dussès, D., Sémon, E., Robert, A., Cancello, E., Lenz, M., Valterovà, I., Bordereau, C., 2010. Identification of multi-component trail pheromones in the most evolutionarily derived termites, the Nasutitermitinae (Termitidae). Biol. J. Linnean Soc. 99, 20-27.

Sillam-Dussès, D., Kalinová, B., Jiroš, P., Brezinová, A., Cvacka, J., Hanus, R., Sobotník, J., Bordereau, C., Valterová, I., 2009. Identification by GC-EAD of the two-component trail-following pheromone of Prorhinotermes simplex (Isoptera, Rhinotermitidae, Prorhinotermitinae). J. Insect Physiol. 55, 751-757.

Sillam-Dussès, D., Sémon, E., Moreau, C., Valterová, I., Sobotník, J., Robert, A., Bordereau, C., 
2005. Neocembrene A, a major component of the trail-following pheromone in the genus Prorhinotermes (Insecta, Isoptera, Rhinotermitidae). Chemoecology 15, 1-6.

Smith, M.R., 1965. House-infesting ants of the eastern United States. Their recognition, biology, and economic importance. United States Department of Agriculture, Technical Bulletin 1326: ii, $105 \mathrm{p}$.

Sorrells, T.R., Kuritzky, L.Y., Kauhanen, P.G., Fitzgerald, K., Sturgis, S.J., Chen J., Dijamco, C.A., Basurto, K.N., Gordon, D.M., 2011. Chemical defense by the native winter ant (Prenolepis imparis) against the invasive Argentine ant (Linepithema humile). PLoS ONE 6(4): e18717. doi:10.1371/journal.pone.0018717.

Thompson, C.R., 1990. Ants that have pest status in the United States. In: Vander Meer RK, Jaffe K, Cedeno A, editors. Applied myrmecology: a world perspective. Boulder, CO. 741 p.: Westview Press. p 51-67.

Vanderah, D.J., Rutledge, N., Schmitz, F.J., Ciereszko, L.S., 1978. Marine natural products: cembrene-A and cembrene-C from a soft coral, Nephthea species. J. Org. Chem. 43, $1614-1616$.

Wang, L., Chen, J., 2015. Fatty amines from little black ants, Monomorium minimum, and their biological activities against red imported fire ants, Solenopsis invicta. J. Chem. Ecol. 41, 708-15.

Waterhouse, J.S., Hudson, M., Pickett, J.A., Weldon P.J., 2001. Volatile components in dorsal gland secretions of the white-lipped peccary, Tayassu pecari, from Bolivia. J. Chem. Ecol. 27, 2459-2469.

Waterhouse, J.S., Ke, J., Pickett, J.A., Weldon P.J., 1996. Volatile components in the dorsal 
gland secretion of the collared peccary, Tayassu tajacu (Tayassuidae, Mammalia). J. Chem. Ecol. 22, 1307-1314.

Wiemer, D.F., Meinwald, J., Prestwich, G.D., and Miura, I. 1979. Cembrene A and (3Z)cembrene A: diterpenes from a termite soldier (Isoptera Termitidae Termitinae). J. Org. Chem. 44, 3950-3952. 
Table 1. Compounds that have been previously identified in the venom of little black fire ants, Monomorium minimum.

\begin{tabular}{|c|c|c|c|}
\hline Compounds & $\mathbf{R}_{1}$ & $\mathbf{R}_{2}$ & References \\
\hline & $\left(\mathrm{CH}_{2}\right)_{4} \mathrm{CH}=\mathrm{CH}_{2}$ & $\left(\mathrm{CH}_{2}\right)_{7} \mathrm{CH}=\mathrm{CH}_{2}$ & \multirow{2}{*}{ Lange et al. 1989} \\
\hline & $\left(\mathrm{CH}_{2}\right)_{4} \mathrm{CH}=\mathrm{CH}_{2}$ & $\left(\mathrm{CH}_{2}\right)_{8} \mathrm{CH}_{3}$ & \\
\hline \multirow{3}{*}{$\mathrm{R}_{1} / \mathrm{N}^{\prime}$} & $\left(\mathrm{CH}_{2}\right)_{4} \mathrm{CH}=\mathrm{CH}_{2}$ & $\left(\mathrm{CH}_{2}\right)_{7} \mathrm{CH}=\mathrm{CH}_{2}$ & $\begin{array}{l}\text { Jones et al. 1982; Lange et al } \\
1989\end{array}$ \\
\hline & $\left(\mathrm{CH}_{2}\right)_{4} \mathrm{CH}=\mathrm{CH}_{2}$ & $\left(\mathrm{CH}_{2}\right)_{8} \mathrm{CH}_{3}$ & Lange et al. 1989 \\
\hline & $\left(\mathrm{CH}_{2}\right)_{5} \mathrm{CH}_{3}$ & $\left(\mathrm{CH}_{2}\right)_{8} \mathrm{CH}_{3}$ & Lange et al. 1989 \\
\hline$\left.\mathrm{R}_{1}\right|_{\mathrm{N}^{\prime}} ^{\prime}$ & $\left(\mathrm{CH}_{2}\right)_{4} \mathrm{CH}=\mathrm{CH}_{2}$ & $\left(\mathrm{CH}_{2}\right)_{7} \mathrm{CH}=\mathrm{CH}_{2}$ & Jones et al. 1982 \\
\hline & & & Wang and Chen, 2015 \\
\hline & & & ang and Chen, 2015 \\
\hline
\end{tabular}




\section{Figure Legends}

Figure 1. Synthesis scheme for 9-decenyl-1-amine (4)

Figure 2. New amines and terpenes identified in the venom of little black ants Monomorium minimum. (E,E)-7,11,15-trimethyl-3-methylene-1,6,10,14-hexadecatetraene ( $\beta$-springene) and (E,E,E)-1-isopropenyl-4,8,12-trimethylcyclotetradeca-3,7,11-triene (neocembrene) were found only in queens.

Figure 3. Alkaloids found in the venom of the little black ants, Monomorium minimum. A, $\mathrm{B}, \mathrm{C}, \mathrm{D}$, and $\mathrm{E}$ were detected in every sample of both workers and queens and $\mathrm{F}$ only in workers. $\mathrm{G}$ and $\mathrm{H}$ was observed in both workers and queens, but not in every sample. Relative peak area of each alkaloid in the peak area of total alkaloids is shown in Fig S15.

Figure 4. Poison and Dufour's glands in Monomorium minimum queen. $\beta$-springene and neocembrene were only found in the Dufour's gland. 


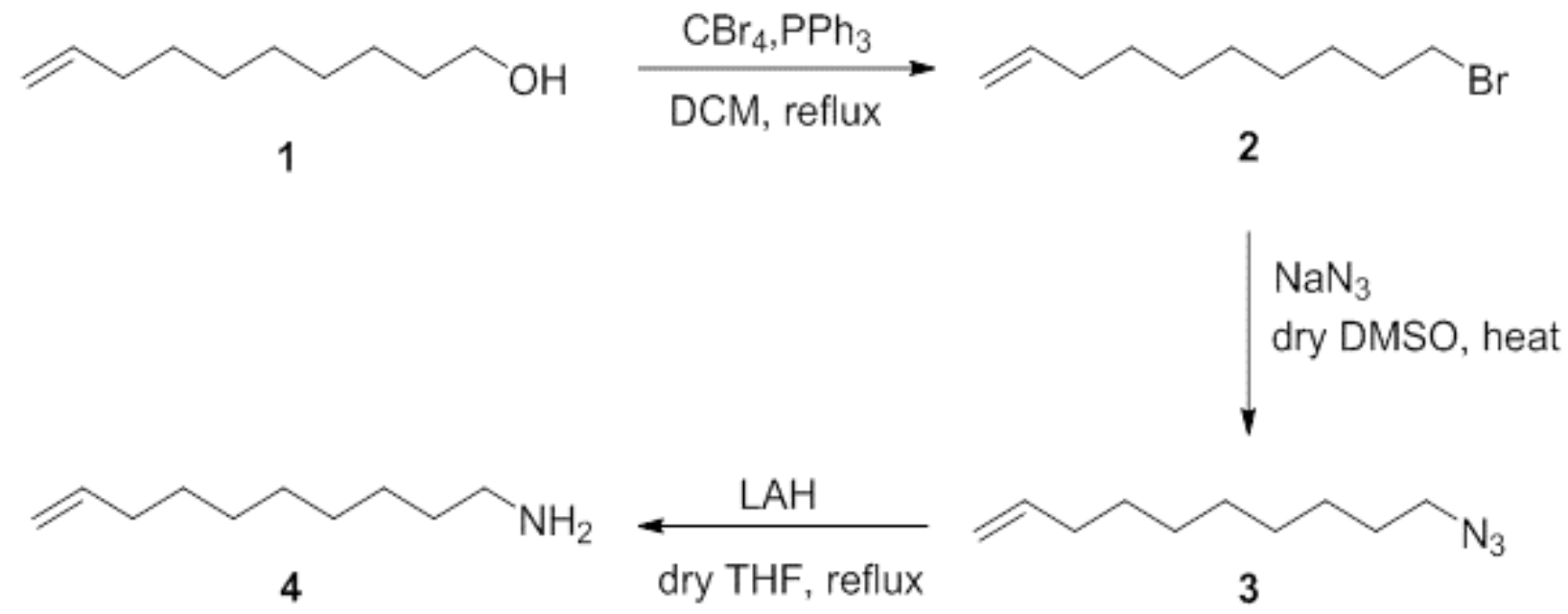



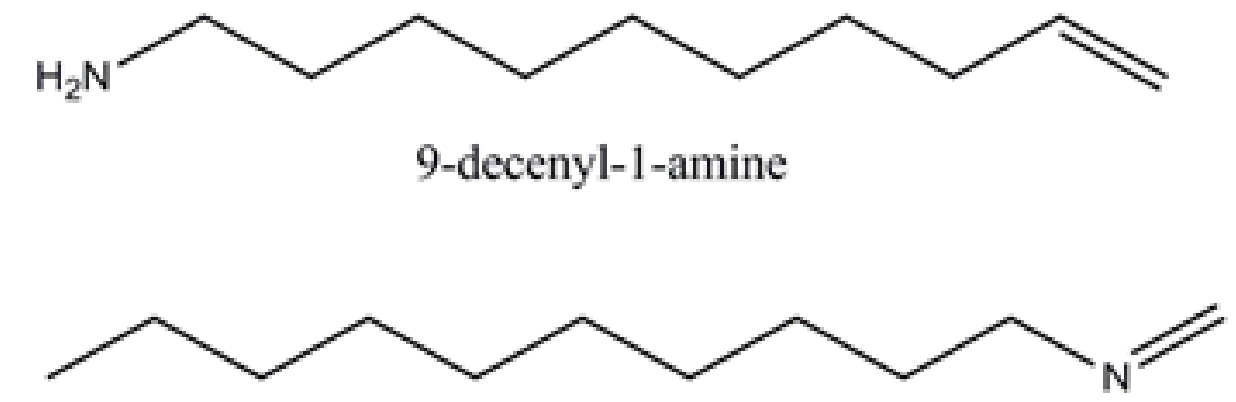

$\mathrm{N}$-methylenedecan-1-amine

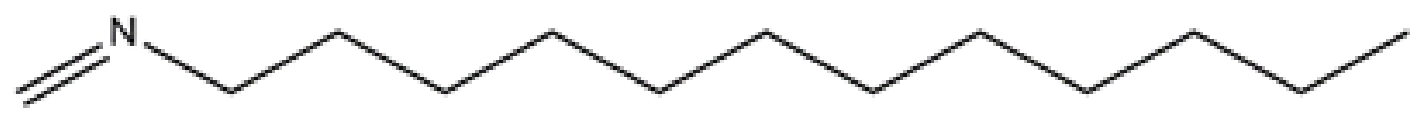

N-methylenedodecan-1-amine

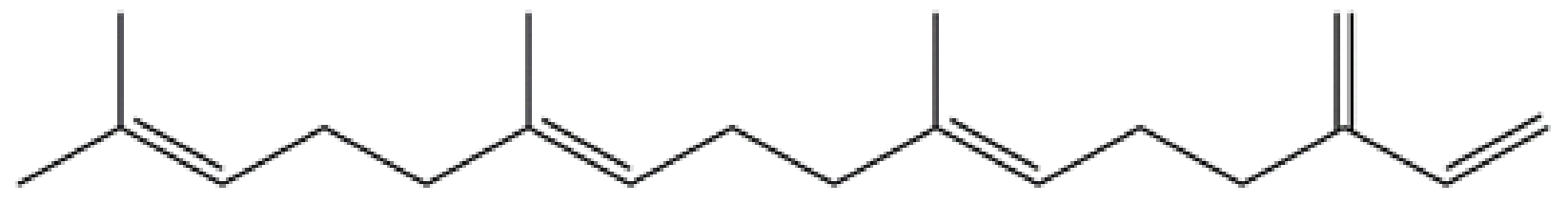

(E,E)-7,11,15-Trimethyl-3-methylene-1,6,10,14-hexadecatetraene

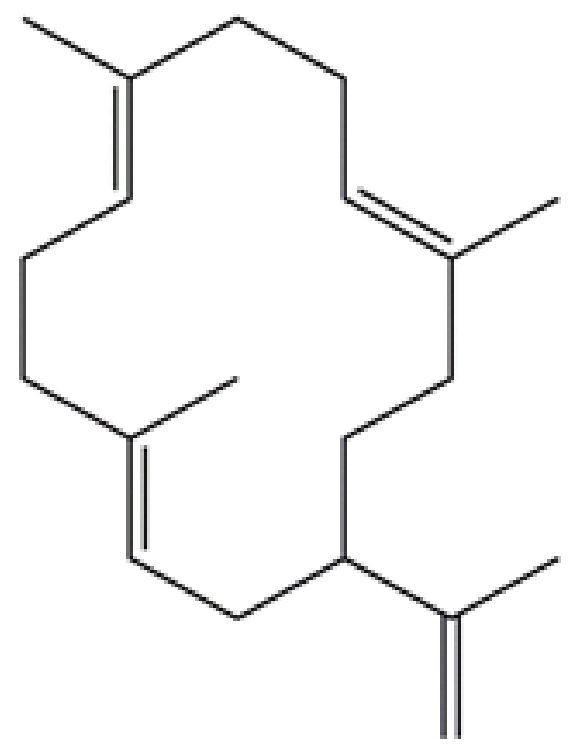

(E,E,E)-1-isopropenyl-4,8,12-trimethylcyclotetradeca-3,7,11-triene 
$\checkmark$<smiles>C=CCCCCCCCC1CCC(CCCCC=C)=N1</smiles><smiles>C=CCCCCC1=NC(CCCCCCCCC)CC1</smiles><smiles>C=CCCCCCCCC1CCC(CCCCC=C)N1</smiles><smiles>C=CCCCCC1CCC(CCCCCCCCC)N1</smiles><smiles>CCCCCCCCCC1CCC(CCCCCC)N1</smiles><smiles>C=CCCCCCCCC1CCC(CCCCC=C)N1C</smiles><smiles>C=CCCCCC1CCC(CCCCCCCCC)N1C</smiles> 


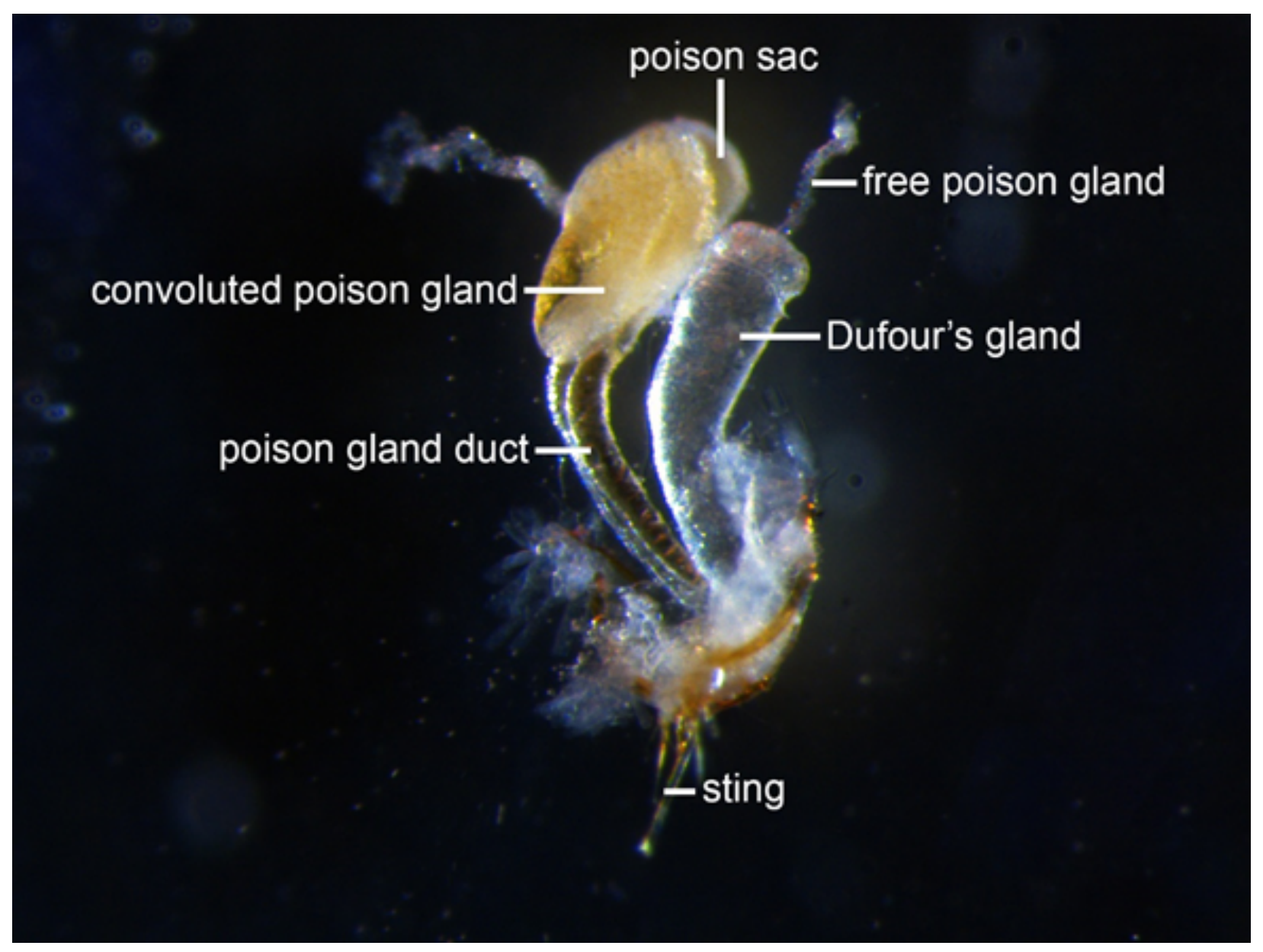

